\title{
FIB Induced Damage Examined with the Low Energy SEM
}

\author{
Š́rka Mikmeková ${ }^{1,2}, K_{\text {Kenji Matsuda }}^{3}$, Katsumi Watanabe ${ }^{2}$, \\ Susumu Ikeno ${ }^{3}$, Ilona Müllerová ${ }^{1}$ and Luděk Frank ${ }^{1}$ \\ ${ }^{1}$ Institute of Scientific Instruments of the ASCR, v.v.i., Královopolská 147, 61264 Brno, Czech Republic \\ ${ }^{2}$ Graduate School of Science and Engineering for Education, University of Toyama, Toyama 930-8555, Japan \\ ${ }^{3}$ Graduate School of Science and Engineering for Research, University of Toyama, Toyama 930-8555, Japan
}

\begin{abstract}
The surface morphology of pure $\mathrm{Mg}$ was studied by means of the cathode lens mode equipped scanning low energy electron microscope after bombarding with $\mathrm{Ga}^{+}$ions at various energies $(10,20,30$, and $40 \mathrm{keV})$ and incident angles $\left(0^{\circ}, 30^{\circ}, 45^{\circ}\right.$, and $\left.60^{\circ}\right)$. In accordance with the Bradley-Harper theory at off-normal angles of incidence ripples were observed on the irradiated areas. The Monte Carlo program SRIM2008 was used to estimate the sputtering yield and damage depth. [doi:10.2320/matertrans.MB201005]
\end{abstract}

(Received September 6, 2010; Accepted November 9, 2010; Published December 22, 2010)

Keywords: scanning low energy electron microscopy, focused ion beam, beam induced damage, sputtering

\section{Introduction}

In recent years the focused ion beam (FIB) technique has found broad applications in the field of materials science. It represents an extremely important tool for site-specific analysis as well as for deposition and ablation of materials. One of the most important applications of FIB technique is preparation of the samples for observation in the transmission electron microscope. However, the FIB can induce reconfiguration or destruction of the specimen structure and in crystalline materials it can create an amorphous layer on the surface. Detailed studies of the ion induced damage have been mainly performed on materials used in the semiconductor industry, especially on $\mathrm{Si}$, InP, and GaAs single crystals, and only little data exists for other materials. ${ }^{1)}$ Therefore we decided to investigate the $\mathrm{Ga}^{+}$ion damage of pure $\mathrm{Mg}$ as a material frequently investigated in our laboratory.

The ion beam bombardment can produce changes in the surface topography on bottom of the crater and so induced morphology requires detailed characterization. SEM is a technique most used in analyzing the surface topography. However, if vertical dimensions of the induced morphology are too small, it became difficult to achieve complete characterization. In fact, since decreasing primary ion beam energy leads to reduction of the relief height, SEM seems even more suitable technique for this purpose. The Scanning Low Energy Electron Microscopy (SLEEM) method is a promising modification to the SEM owing to its high sensitivity to the surface topography.

\section{Experimental}

\subsection{Sample}

The material under investigation was a commercial purity $\mathrm{Mg}$ (99.9 mass\%). The sample surface was prepared by mechanical polishing and electro-polishing in order to remove any remnant damaged layers and surface irregularities. Finally, the sample was annealed in air for $12 \mathrm{~h}$ at $350^{\circ} \mathrm{C}$.

\subsection{Instruments}

In our experiment a FIB System (Hitachi Dual Beam FB2100 workstation) with $\mathrm{Ga}$ ion source was used for milling patterns. The FIB column was operated at accelerating voltages from 10 to $40 \mathrm{keV}$ with the maximum beam current of $30 \mathrm{nA}$ at $40 \mathrm{keV}$, the maximum beam current density of $25 \mathrm{~A} / \mathrm{cm}^{2}$ at $40 \mathrm{keV}$ and the spot size of $6 \mathrm{~nm}$ at $40 \mathrm{keV}$. The incidence angle between the ion beam and the sample normal can vary from $0^{\circ}$ to $60^{\circ}$.

Microstructure of the milled patterns was investigated in the SEM-Hitachi S-3500H equipped with the cathode lens (CL) system.

\section{SLEEM and the CL Mode}

Wide range of analytical techniques exists that may be used for characterizing surface topography with the Atomic Force Microscopy (AFM) and the Scanning Electron Microscopy (SEM) as those most commonly used. ${ }^{2}$ Specific way to visualizing the specimen surface at high sensitivity is to use the cathode lens (CL) mode in the SEM. ${ }^{3)}$ The CL is a zero working distance electrostatic lens with the negatively biased specimen serving as the cathode and the earthed scintillator of the detector as the anode of the CL. If a through-the-lens detector is applied, the pole piece nose of the objective lens can play the role of the anode. Primary electrons are retarded in the CL field and emitted electrons are collimated toward the optical axis and accelerated toward the detector. Important circumstance is that even the backscattered electrons (BSE) emitted under large angles with respect to the surface normal, which are abandoned in a standard SEM, are available now for the detection. This signal contribution has proven itself bearing enhanced crystallographic information. ${ }^{4,5)}$

Using the SLEEM offers several advantages. When lowering energy of the electron beam, the range of primary electrons shortens (Fig. 1) and the secondary electron (SE) yield grows. As a result, the beam-specimen interaction is more localized, charging artifacts drop off and the depth of 


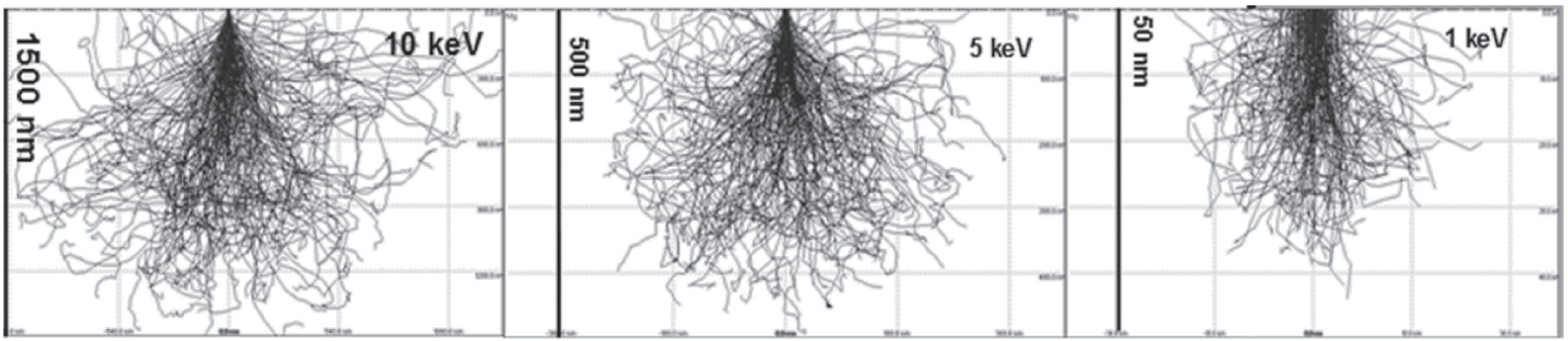

Fig. 1 Comparison of the interaction volume of $10 \mathrm{keV}, 5 \mathrm{keV}$ and $1 \mathrm{keV}$ electrons in $\mathrm{Mg}$. The electrons trajectories were simulated by means of the Monte Carlo simulation software CASINO. ${ }^{6}$

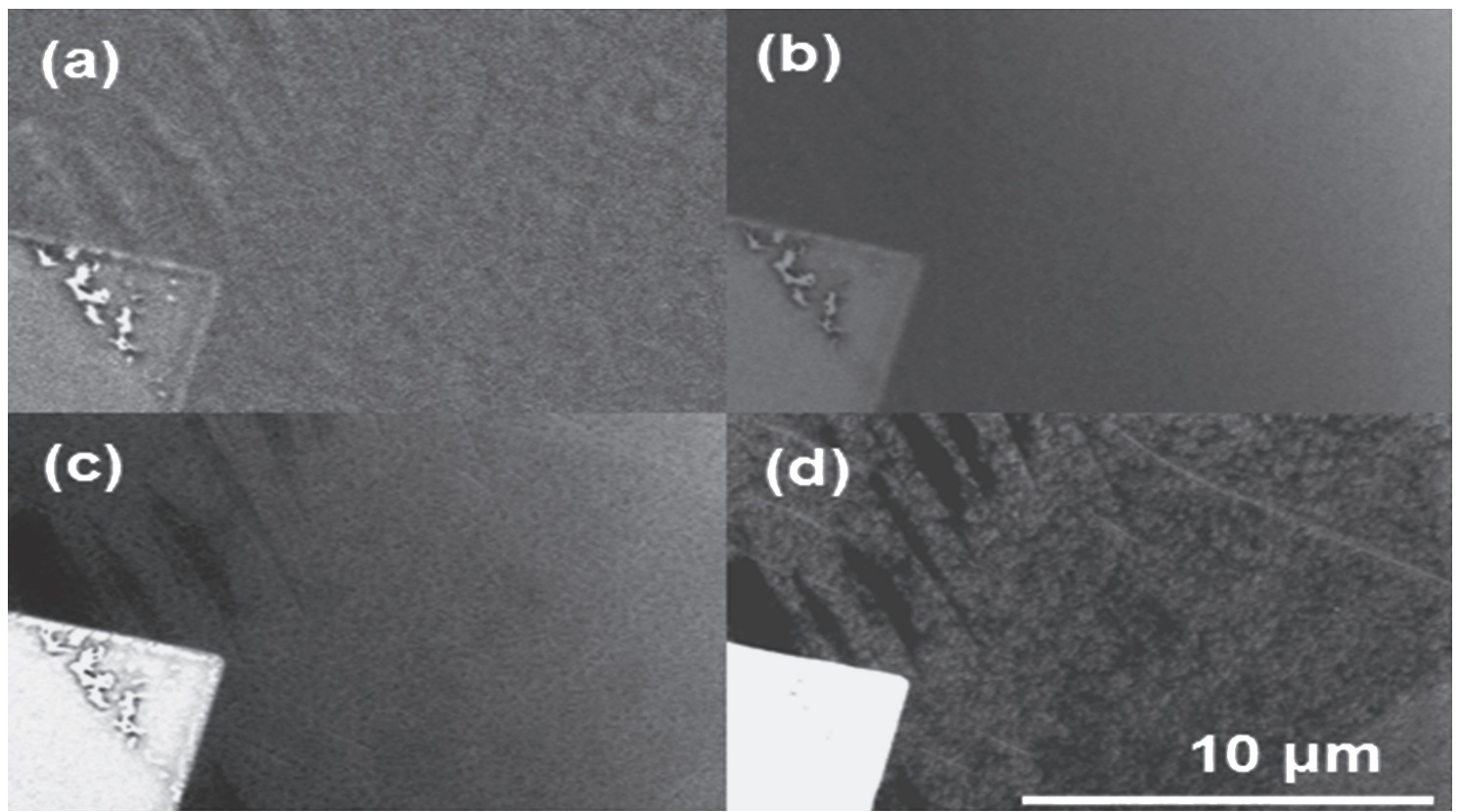

Fig. 2 Micrographs of the metallographically polished Mg surface: conventional SE image at $10 \mathrm{keV}$ (a), conventional BSE image at $10 \mathrm{keV}(\mathrm{b})$, and SLEEM images at $5 \mathrm{keV}$ (c) and $1 \mathrm{keV}(\mathrm{d})$.

radiation damage of the specimen decreases. Improvement in the topographic contrast at lower primary beam energies is demonstrated in Fig. 2.

\section{Ion Beam Induced Damage and Artifacts}

In the FIB instrument, $\mathrm{Ga}$ ions emitted from their source are accelerated by high voltage and focused with electrostatic lenses to a beam sputtering the specimen surface via collisions of the high energy ions with target atoms. The penetration depth of ions into the target is dependent on the beam energy, ion impact angle, type of ions and chemical composition of the target. Using the Monte Carlo simulation program called SRIM, ${ }^{7)}$ the projected $\mathrm{Ga}^{+}$ion range for $\mathrm{Mg}$ has been predicted at the ion beam energies and impact angles used in this study. The ion ranges are represented schematically by the diagrams in Fig. 3 and Fig. 4. The ions penetrate in depth and lose their energy due to interactions with atoms of the specimen that start heavily vibrate with respect to lattice points or even break loose, which results in a collision cascade. When energy is transferred to a near-surface atom, it can overcome the surface binding energy and escape from the specimen.

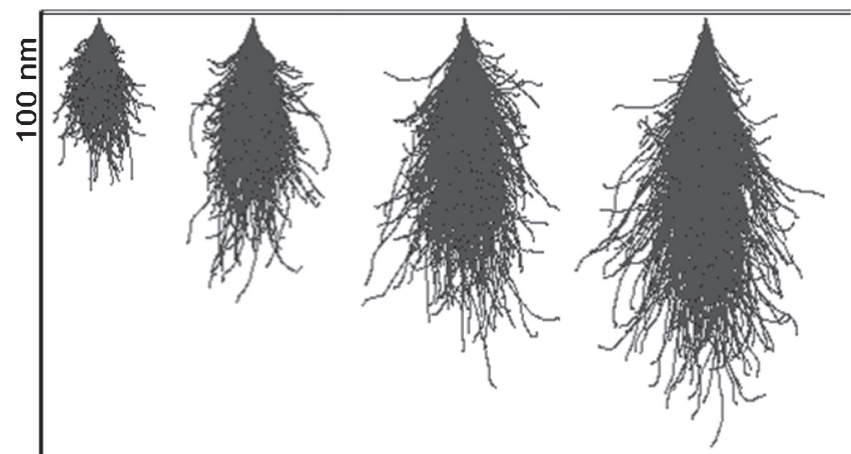

Fig. 3 Monte Carlo simulation of the trajectories of $1000 \mathrm{Ga}$ ions bombarding at normal incidence the pure $\mathrm{Mg}$ surface at the operation voltages from the left $10 \mathrm{keV}, 20 \mathrm{keV}, 30 \mathrm{keV}$ and $40 \mathrm{keV}$.

Artifacts created by the ion beam radiation are the surface layers of amorphization and redeposition, surface roughness, induced lattice defects, atomic mixing and sample alterations due to beam heating. We will focus mainly on influence of the ion energy and impact angle of the $\mathrm{Ga}$ ions on the surface topography. 


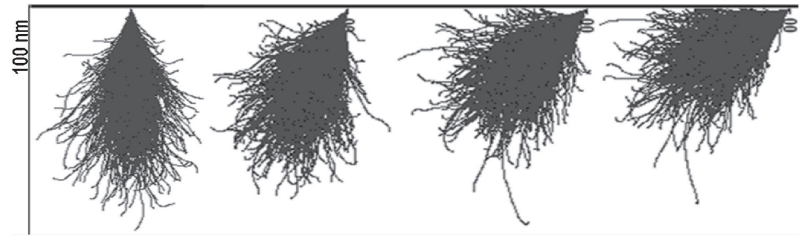

Fig. 4 Monte Carlo simulation of the trajectories of $1000 \mathrm{Ga}$ ions bombarding the pure $\mathrm{Mg}$ surface at the impact angles between the target surface normal and the ion beam of $0^{\circ}, 30^{\circ}, 45^{\circ}$ and $60^{\circ}$; the ion beam energy was $40 \mathrm{keV}$ in all cases.

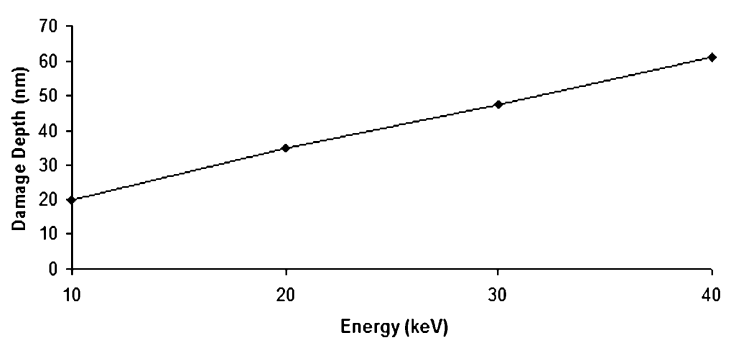

Fig. 5 Calculated damage depth as a function of the incident ion beam energy.

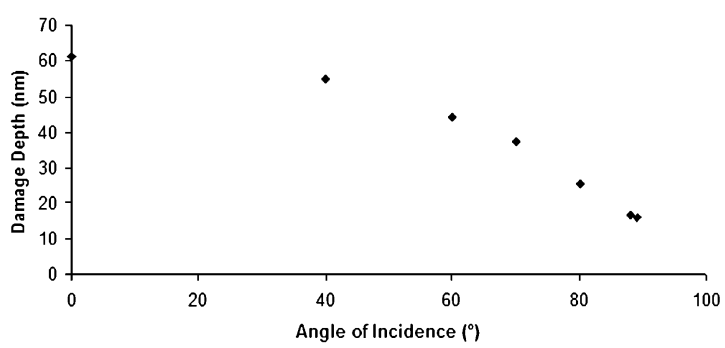

Fig. 6 Calculated damage depth as a function of the angle of incidence.

\subsection{Thickness of the damaged layer}

The best-known damage introduced during the FIB bombardment is formation of an amorphous layer due to Ga implantation and the knock-on damage. Thickness of the amorphous layer is independent on the beam current and etching time, and depends on the beam energy, angle of incidence and the material being milled. ${ }^{1,7,8)}$ Thickness of the damage (e.g. thickness of amorphous layer) caused by the ion bombardment was estimated by Monte Carlo simulation using the SRIM code and the results are shown in Figs. 5 and 6 vs. the ion beam energy and impact angle. In order to reduce thickness of the amorphous layer on the $\mathrm{Mg}$ surface, low impact angle and low energy of ions should be used. The study will continue with comparison of these calculated data with experimental values obtained by means of a transmission electron microscope.

\subsection{Patterns spontaneously generated with FIB}

Development in the surface topography is extremely sensitive to parameters like chemical composition of the target, type of sputtering ions, beam energy, angle of incidence, temperature, crystallographic orientation, etc. We have studied formation and self-organization of "ripples" and "dots" spontaneously appearing during irradiation of the $\mathrm{Mg}$ specimen with the $\mathrm{Ga}^{+}$ion beam.

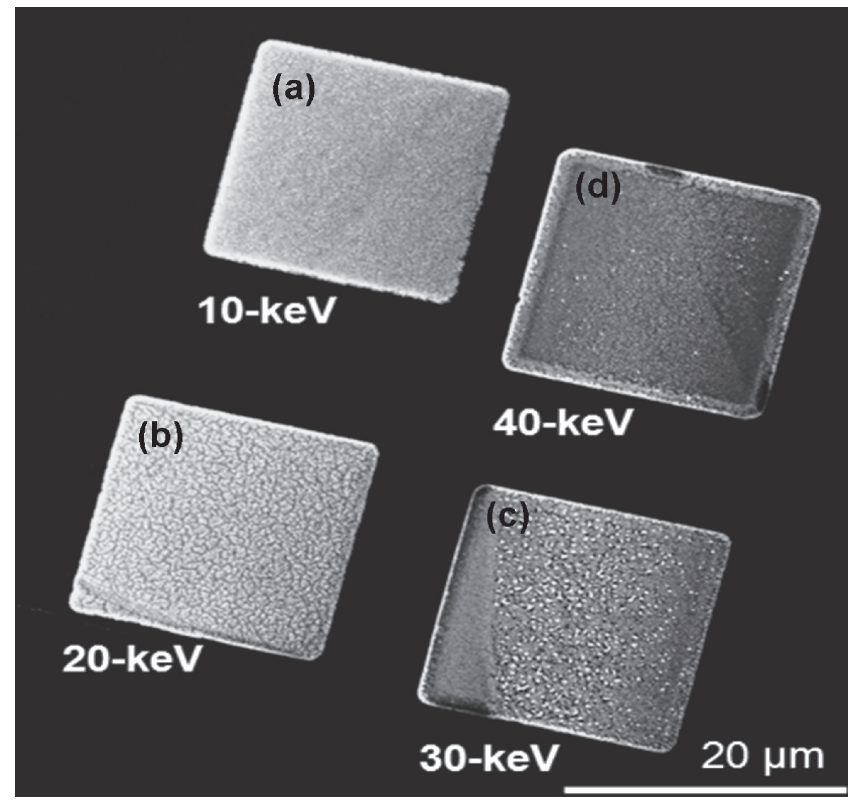

Fig. 7 SLEEM micrograph of four hollows milled in the Mg surface using various energies of the ion beam. The electron impact energy was $1 \mathrm{keV}$.

Bombarding the specimen surface at the normal impact of ions leads to formation of depressions and hillocks. Figure 7 shows the SLEEM micrographs of four milled structures in $\mathrm{Mg}$, acquired in the CL mode at $1 \mathrm{keV}$. These hollows are located on the same crystal grain and dug with beam energies from 10 to $40 \mathrm{keV}$. The beam current was $0.14 \mathrm{nA}(10 \mathrm{keV})$, $0.29 \mathrm{nA}(20 \mathrm{keV}), 0.48 \mathrm{nA}(30 \mathrm{keV})$, and $0.71 \mathrm{nA}(40 \mathrm{keV})$ for the beam spot of $40 \mathrm{~nm}$ in diameter, dwell time of $3 \mu \mathrm{s}$, beam overlap $50 \%$ and the total time for creating each structure of 3 min. The beam impact was normal in all cases. Bottoms of the hollows are shown in Fig. 8 at higher magnification. While the $10 \mathrm{keV}$ ions modify the surface quite moderately (Fig. 8(a)), marked alterations in the surface morphology are obvious at higher energies (Fig. 8(b) and 8(c)) and typical dots appear in Fig. 8(d).

Ion sputtering induced ripples have been produced on surfaces of various materials including metals, semiconductors and amorphous solids. Navez et al. ${ }^{9)}$ showed the low energy ion erosion of glass surfaces leading to formation of self-organized periodic patterns. Bradley and Harper ${ }^{10)}$ developed a continuum model to describe the formation of regular patterns. In this model two competitive forces determine the surface patterns, namely the surface curvature dependent sputtering and the smoothening due to surface diffusion. Two types of patterns can be observed: ${ }^{9-12)}$ for the off-normal incidence of ions we observe regular ripples while at the normal incidence we can observe formation of dots (Fig. 8(d)), which is consistent with the Bradley-Harper theory.

Figure 9 presents the SLEEM micrograph of four recesses in the $\mathrm{Mg}$ surface milled with various impact angles of the FIB. The beam energy was fixed to $1 \mathrm{keV}$ and the beam current to $0.69 \mathrm{nA}$ with the beam spot diameter of $40 \mathrm{~nm}$, the dwell time of $3 \mu$ s and the sputtering time for creation each structure of $3 \mathrm{~min}$. Figure 10 shows the bottoms of these hollows at higher magnification and in Fig. 11 we see the 


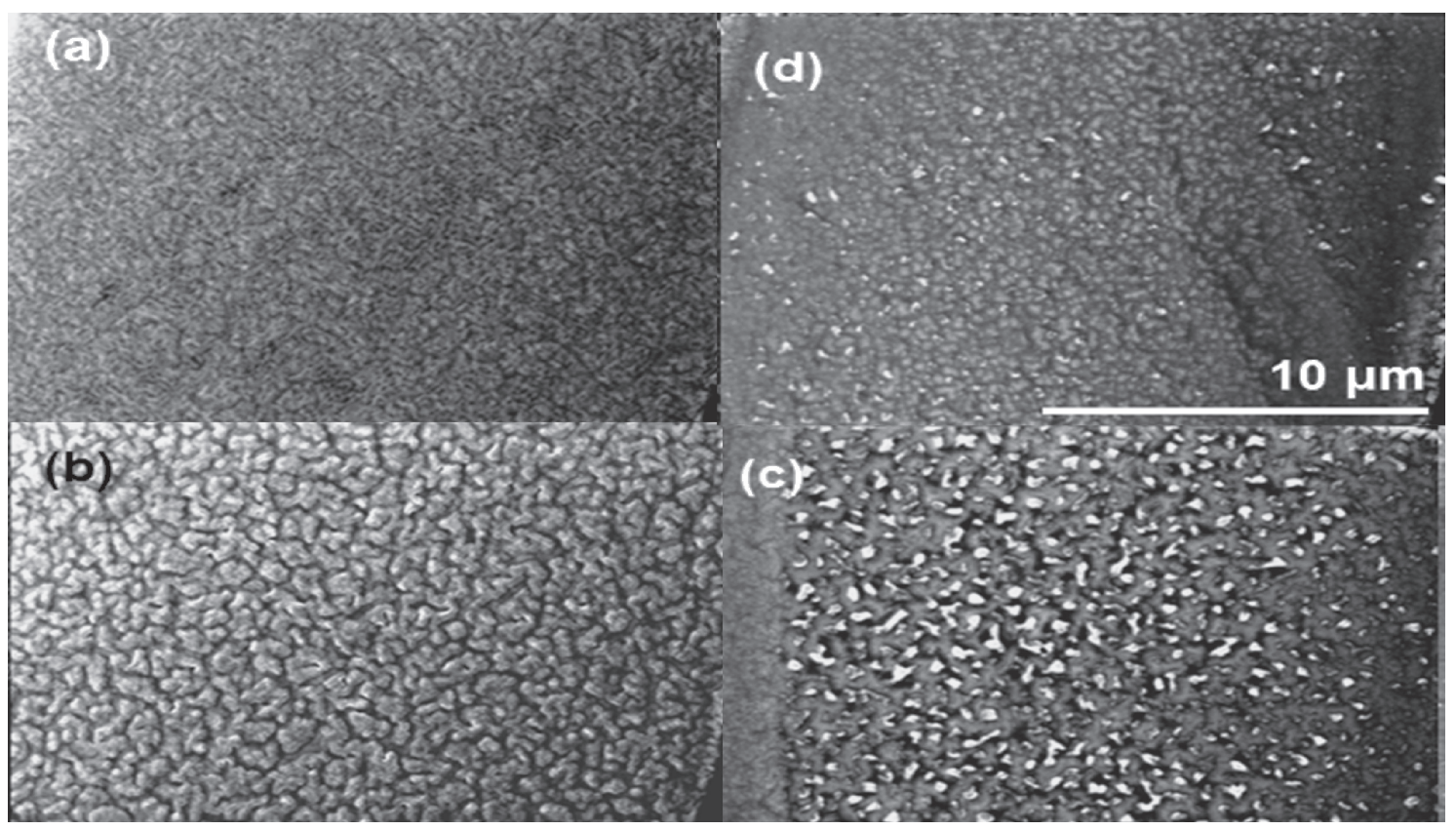

Fig. 8 Magnified images of bottoms of the milled hollows obtained in the SLEEM mode with the $1 \mathrm{keV}$ landing energy of electrons; ion beam energies were $10 \mathrm{keV}$ (a), $20 \mathrm{keV}$ (b), $30 \mathrm{keV}$ (c), and $40 \mathrm{keV}$ (d).

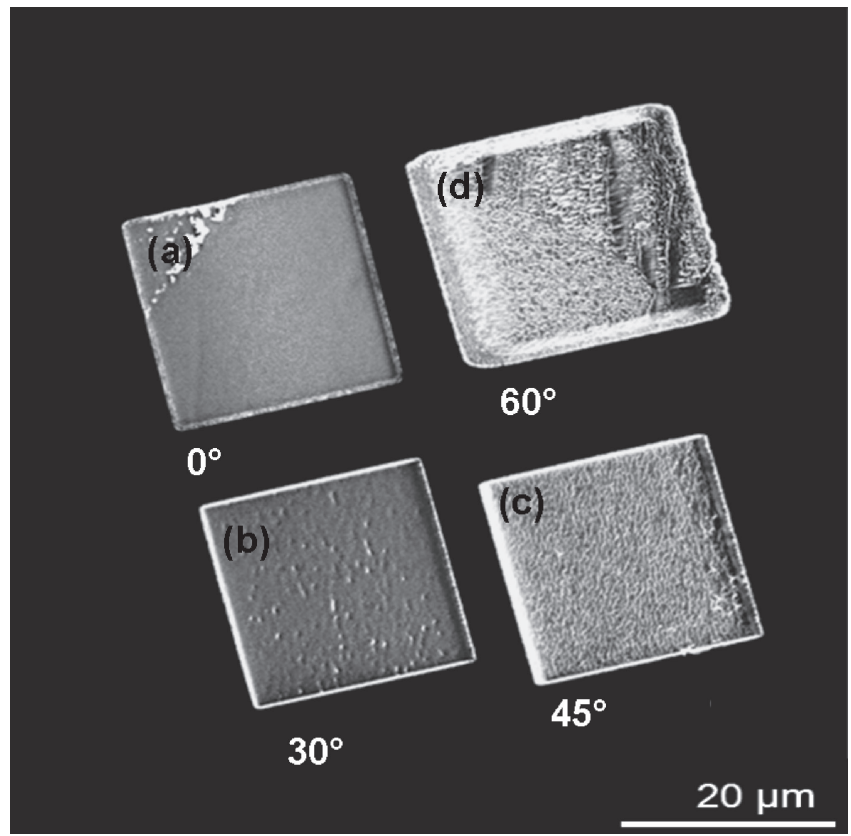

Fig. 9 SLEEM micrograph of four hollows milled in the Mg surface using various impact angles of ions. The electron impact energy was $1 \mathrm{keV}$.

same patterns imaged using the conventional secondary electron (SE) mode revealing presence of grain boundaries and their appearance on the hollow bottoms. The surface morphology observed is in good agreement with theoretical prediction, namely the ripples appear on the $\mathrm{Mg}$ surface at off-normal impact angles of ions.

\subsection{Sputtering}

When an ion penetrates in the sample surface, it loses its kinetic energy or momentum through interaction with atoms of the material and when this transferred energy overcomes the surface binding energy, a near-surface atom can escape from the sample. Efficiency of the sputtering process (the sputtering yield) depends on several factors, namely the target material, type of ions, crystal orientation, surface roughness, and most dramatically on the ion beam impact angle. ${ }^{13)}$ The sputtering yield grows with the angle of incidence and reaches its maximum at about $80^{\circ}$ from the surface normal. Figure 12 shows the impact angle dependence of the sputtering yield expressed as the number of sputtered atoms per incoming ion, obtained via simulation using the Monte Carlo program SRIM2008. Increase in the hollow depth with the impact angle of ions is obvious in Fig. 9 and even more clearly in Fig. 11.

For $40 \mathrm{keV} \mathrm{Ga}$ ions and normal angle of incidence on the pure $\mathrm{Mg}$ specimen, the sputtering yield predicted by the SRIM program is 5.51 atoms per ion. For practical use it can be expressed as $0.80 \mu \mathrm{m}^{3} / \mathrm{nC}$. Knowing the density of $\mathrm{Mg}$, we can calculate the volume removed and the depth of the milled pattern to be $257 \mathrm{~nm}$. This result of simulations is in agreement with experimental data from the AFM measurement providing an average value of $280 \mathrm{~nm}$. The AFM measured depth of the milled pattern is larger than the calculated one owing to the redeposition effect.

\section{Conclusion}

Pure magnesium surface irradiated at normal and offnormal impact angles with the focused ion beam were studied as regards its microrelief. The surface topography formed on the irradiated areas was investigated by the SLEEM method for the first time. The experimental results have shown the surface topography dependent on the beam parameters in a way well fitting theoretical predictions. The damage depth and sputtering yield were calculated with the Monte Carlo program SRIM2008. 


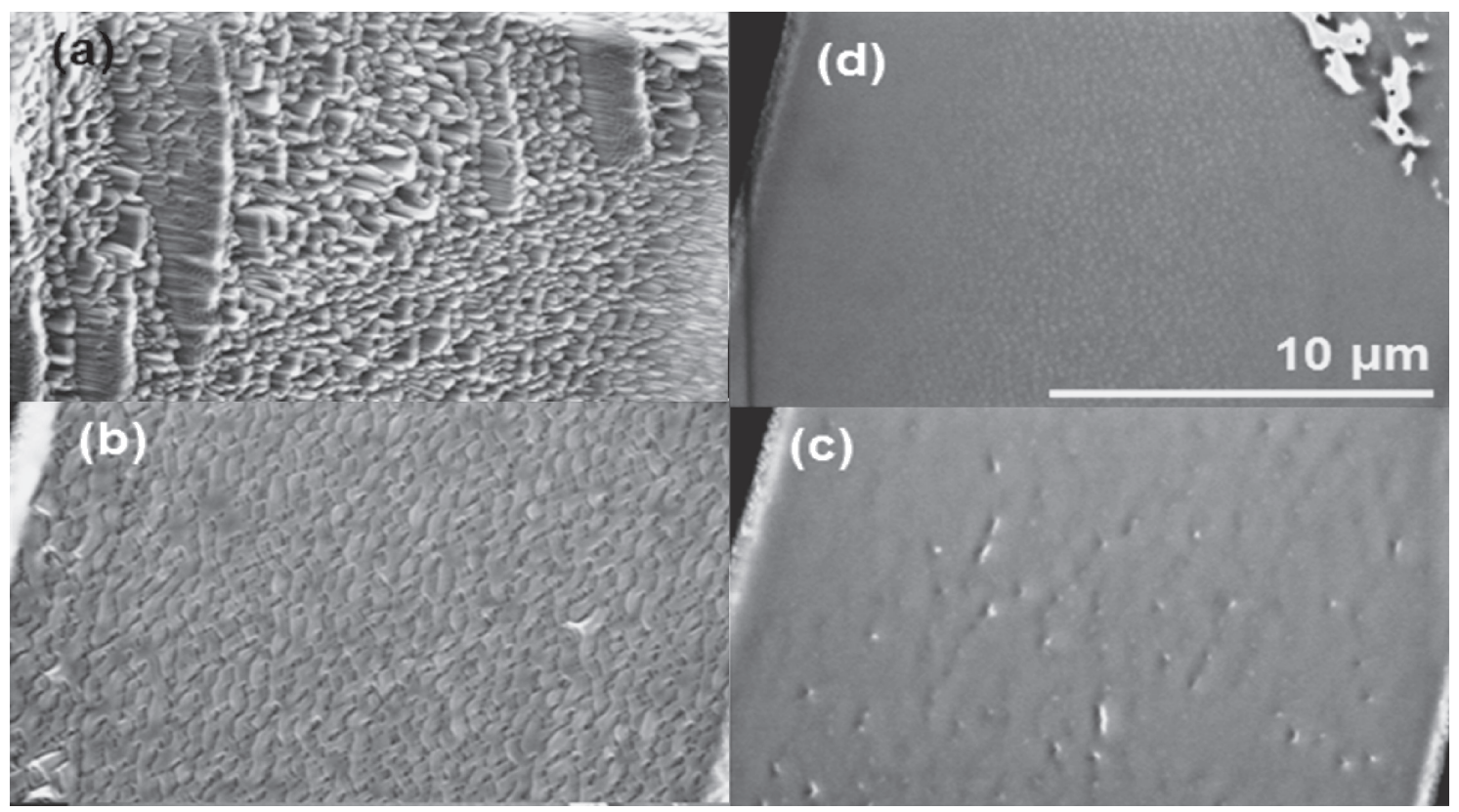

Fig. 10 Magnified images of bottoms of the milled hollows obtained in the SLEEM mode with the $1 \mathrm{keV}$ landing energy of electrons; ion beam impact angles were $60^{\circ}$ (a), $45^{\circ}(\mathrm{b}), 30^{\circ}$ (c), and $0^{\circ}$ (d) from surface normal.

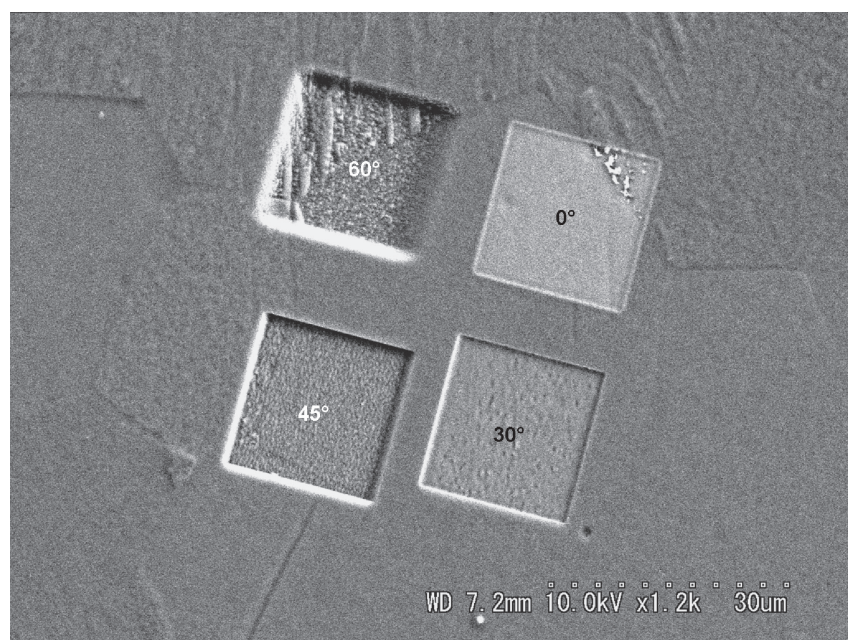

Fig. 11 The group of hollows from Fig. 9 shown using the conventional SE mode.

\section{Acknowledgements}

The study was partially supported by the Czech Eureka project no. OE08012. The authors would like to thank Mr. Hiroshi Takabatake for his help with AFM measurement and analysis.

\section{REFERENCES}

1) N. I. Kato: J. Electron Microsc. 53 (2004) 451-458.

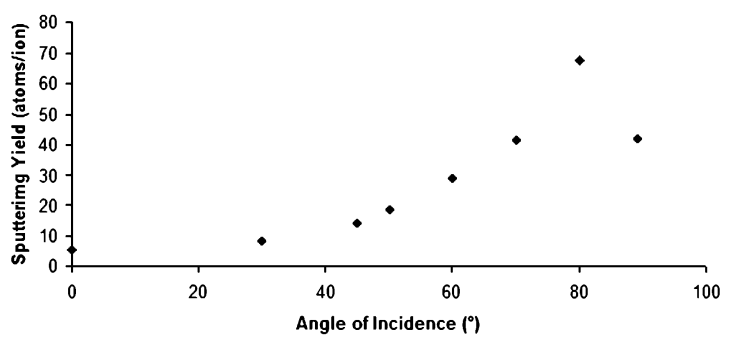

Fig. 12 Dependence of the sputtering yield on the angle of ion incidence as predicted by the SRIM program; the ion beam energy was $40 \mathrm{keV}$.

2) www.veeco.com

3) I. Müllerová and L. Frank: Adv. Imag. Electron Phys. 128 (2003) 309_ 343.

4) I. Müllerová, I. Konvalina and L. Frank: Mater. Trans. 48 (2007) 940943.

5) Š. Mikmeková, M. Hovorka, I. Müllerová, O. Man, L. Pantělejev and L. Frank: Mater. Trans. 51 (2010) 292-296.

6) www.gel.usherbrooke.ca/casino/What.html

7) www.srim.org

8) D. Kiener, C. Motz, M. Rester, M. Jenko and G. Dehm: Mat. Sci. Eng. A 459 (2007) 262-272.

9) M. Navez, D. Chaperot and C. Sella: Comptes Rendus Academie des Science 254 (1962) 240-248.

10) R. M. Bradley and J. M. Harper: J. Vac. Sci. Technol. A 6 (1988) 23902395.

11) A. Cuenat and M. J. Aziz: Mat. Res. Soc. Symp. Proc. 696 (2002) 281286.

12) H. X. Qian, W. Zhou, Y. Q. Fu, B. K. A. Ngoi and G. C. Lim: Appl. Surf. Sci. 240 (2005) 140-145.

13) J. J. L. Mulders, D. A. M. de Winter and W. J. H. C. P. Duinkerken: Microele. Eng. 84 (2007) 1540-1543. 